Article

\title{
Influence of Milling Parameters on Mechanical Properties of AA7075 Aluminum under Corrosion Conditions
}

\author{
María Jesús Martín*(i), María José Cano, Germán Castillo ${ }^{\circledR}$, Manuel José Herrera \\ and Francisco Martín (1) \\ Civil, Material and Manufacturing Engineering Department, EII, University of Málaga, 29071 Málaga, Spain; \\ mjcano@uma.es (M.J.C.); gcastillo@uma.es (G.C.); mherrera@uma.es (M.J.H.); fdmartin@uma.es (F.M.) \\ * Correspondence: mjmartin@uma.es (M.J.M.); Tel.: +34-951-952-243
}

Received: 1 July 2018; Accepted: 14 September 2018; Published: 17 September 2018

check for updates

\begin{abstract}
The paper describes an experimental study developed on the AA7075 T651, which is an aluminum alloy extensively used in the aeronautical industry. This work presents a double approach of investigation where there is no literature about previous research. This includes the analysis of the results obtained by the combination of mechanical and chemical actions on the mechanical properties of this material. On the one hand, the combinations of relevant milling parameters (feed rate, cutting speed) on flat samples (flat specimens have been selected by attempting to reproduce with the most accurate way the geometry and the type of machining process known as face milling is usually used in this manufacturing field). On the other hand, the stimulating effect of the corrosion by salt spray on selected batches of specimens was machined in the previous stage. Results from tensile tests performed on the whole of specimens allowed us to evaluate how the main mechanical properties (yield strength, tensile strength, and elongation at break) have been affected by the processes applied. Elongation at the break presents a reduction in an inverse order to feed a rate increase (up to $24.5 \%$ ) and this reduction is extended (additional 19.17\%) in specimens under corrosion conditions, which results in a greater fragility of the material.
\end{abstract}

Keywords: machining; mechanical properties; corrosion; aluminum; flat specimen; AA7075

\section{Introduction}

The aerospace industry requires materials with exceptional performance and long-term reliability. In this sense, aluminum and its alloys is one of the materials used most commonly in this field. This is thanks to some of its unique characteristics such as a high strength-to-weight, ease of fabrication, or its relative low cost. There are several different types of aluminum used but the $7075 \mathrm{Al}$ alloy remains the baseline [1-3]. Part of this is due to its good balance of properties required for aerospace applications. Additionally, it is possible to apply sequences of mechanical and thermal treatments to produce annealed states as well as major combinations of characteristics through variations in treatment conditions. Taking into account that AA7075 T651 is widely used in aeronautics, this alloy will be the focus of this research.

Nowadays, advanced composites consisting of a combination of high-strength stiff fibers embedded in a common matrix material [4] or titanium alloys are also widely being used in the aerospace industry. Both compete with aluminum [5,6] but present manufacturing difficulties especially in machining processes. Aluminum alloys can be machined rapidly and economically because of their micro-constituents that have important effects on machining characteristics [7-9]. In this way, numerous conventional machining processes can be performed on these materials (milling, drilling, 
and turning) by taking into account the different geometric characteristics required in each process [10]. Concretely, manufacturing of lightened plates of aluminum by face milling or profile milling is one of the most applied machining processes. Therefore, in this project, this type of machining process will be performed on the flat specimen to study in the attempt to reproduce as accurately as possible the way in which aircraft structures are made of. We studied the influence of different dominant parameters of this type of machining such as cutting speed, feed per tooth or cutting depth, fixing values of cutting speed and depth of cut, and taking the feed rate as the parameter to establish a degree of freedom in this experiment due to its significant influence on the roughness surface of the parts machined [11-15]. For this variable, a range of three values will be applied.

Traditionally, cutting fluids have been widely used in metalworking processes by providing cooling and lubrication while also preventing corrosion and facilitating the ejection of cut metal. However, their composition, usage, and disposal can negatively impact the environment and the health of exposed individuals by making necessary their reduction and even their elimination [16-18]. Specifically, in aluminum machining, the mixture of chip and cutting fluid make more difficult a correct recycling [19]. Other times, aluminum alloys are machined jointly with different types of materials such as composites or polymers reinforced with carbon fiber, which do not have a satisfactory performance with cutting fluids. Because of this, dry cutting is presented as an alternative to minimize or avoid the use of cutting fluid [20-23]. However, dry machining demands more rigorous requirements in machining operations and affects largely the surface finish [24].

Taking as a starting point the previous machining conditions, it is needed to define combinations of cutting parameter values to improve the mechanical behavior of the material studied [25]. This premise will define the first of the three stages of the present project.

Studies about AA7075 alloy hardly exists in literature, which is remarkable when considering that this material is widely used in aeronautic components.

On the other hand, it is widely known that corrosion is a universal enemy whose presence is inevitable in a productive process or any other. Corrosion can be defined as the chemical or electrochemical reaction of a metal or alloy with its surrounding environment and with the consequent deterioration of its properties [26,27]. One of the most obvious manifestations of corrosion is its direct effect on the surface of the metal subject. This allows us to establish that this relationship provokes a stimulant effect on the surface geometric imposed [28] and, therefore, has a greater influence on the variation of the mechanical properties of the material subjected to a corrosive environment.

It is possible to distinguish between corrosion by oxidation of the metal with the formation of metal cations and the dissolution of a metal in other metals or molten salts. There is a form of corrosion in which two effects are superimposed: the first one is chemical or electrochemical, which constitutes the corrosion itself, and the other one is mechanical. For example, the process of corrosion-erosion or corrosion under tension. The basic corrosion reaction is defined by the transit of the metal or alloy from its elementary form to the ionic or combined form (Equation (1)).

$$
\mathrm{Me} \rightarrow \mathrm{Me}^{\mathrm{n}+}+\mathrm{ne}^{-}
$$

$\mathrm{n}$ being the number of free electrons.

To complete the process, electrons must be fixed by affinity (an oxidant) by some substances that are present in the medium in contact such as oxygen. The elemental metal through the corrosion mechanism returns to the combined form by making oxides, sulfides, and more including the state in which metals are usually found in nature and are thermodynamically more stable.

It is possible to classify corrosion processes using different criteria. For example, considering the morphology of the attack, it could be described as uniform or localized (selective corrosion, intergranular attacks, among others) [29,30]. However, the most interesting scientific classification is based on the mechanism that produces this phenomenon. From this point of view, corrosion will be produced electrochemically by electrochemical battery cells on the metallic surface and, therefore, does not produce the same effect on the whole metallic surface due to the cathodic regions not 
being attacked. This type of corrosion appears when metal materials are in contact with electrolytic conductivity media specifically with water, salt solutions, or the simple humidity of the atmosphere and soils. The other fundamental type of corrosion occurs in conditions of absence of humidity on the complete metal surface at high temperatures.

The phenomenon of stress corrosion cracking is typical of alloys including passive ones. This phenomenon is characterized by the appearance of cracks that advance in an approximately normal direction with respect to the application of tension [31,32]. Stress corrosion cracking results from the conjoint action of three components.

(a) Material under tensions higher than a defined threshold, whether applied or residual.

(b) Material susceptible to cracking, determined by the composition of the alloy, its microstructure or its grain size.

(c) Material in contact with a specific aggressive environment for it.

Regarding the first condition, it is important to emphasize that tension cannot only be applied when the alloy is part of a structural element but can be a residual tension arising from its forming process or its thermal history.

Previously described in this project, electrochemical corrosion under wet and saline environment has mainly been reproduced. Nevertheless, it also is possible to consider the stress corrosion cracking phenomenon, which could be implicated because of the notch effect. In our study, the notch effect in the sample will depend on the different levels of machining obtained by means of the variation of the milling parameters.

Machining conditions imposed on specimen batches and the corrosive environment subsequently applied to them allow us to analyze the influence of the ones on the mechanical properties of the material studied. Sometimes corrosion and machining working jointly can cause weakness and fragility of the material, which are able to result in a reduction of its tensile strength $[33,34]$ and yield strength as well as a decrease in its percentage of elongation.

\section{Materials and Methods}

Because of the high interest within the aeronautic scope in the use of light alloys especially aluminum ones, this work is focused on the mechanical behavior analysis of one of the most important alloys used in this field including the AA7075 T651 alloy (thermal treatment and tensile controlled of $1.5 \%$ to $3 \%$ (according to the manufacturer). It starts from the aluminum sheet $8 \mathrm{~mm}$ thick, EN AW7075 $(\mathrm{AlZn} 5,5 \mathrm{MgCu})$ (Table 1). The choice of this thickness is conditioned by the fact that both faces of the sheet are going to be machined under different cutting parameters by following the purpose of doing the analysis of the influence of these machining conditions on samples subject to a corrosive environment. Vibration effects from the machine operation on the work held to the table can produce warps and waves. This situation obliges it to choose a particular initial thickness, according to the last $4 \mathrm{~mm}$ thick. Samples are created by the top face and edge machining. Because the main goal of this work is the study of the influence of the milling parameters on the corrosion effect on the samples and the effect on their mechanical behavior, it is absolutely necessary to perform a controlled material-removal process $[8,12]$.

Table 1. AA7075 alloy composition.

\begin{tabular}{cccccccccccc}
\hline$\%$ & $\mathbf{S i}$ & $\mathbf{F e}$ & $\mathbf{C u}$ & $\mathbf{M n}$ & $\mathbf{M g}$ & $\mathbf{C r}$ & $\mathbf{Z n}$ & $\mathbf{T i}$ & Others Elements & Al \\
\hline Minimum & - & - & 1.20 & - & 2.10 & 0.18 & 5.10 & - & $\mathrm{Zr}+\mathrm{Ti}$ & Total & - \\
Maximum & 0.40 & 0.50 & 2.00 & 0.30 & 2.90 & 0.28 & 6.10 & 0.20 & 0.25 & 0.15 & rest \\
\hline
\end{tabular}

It has been used with the three axes milling machine Kondia K600 with CNC control FAGOR 8050. The rotating face milling cutter is a face mill STD B0 0302 of $63 \mathrm{~mm}$ external diameter with 
a major cutting edge angle (or Entering angle) of $90^{\circ}$ that holds six inserts STD ISO APKT 160408 B0 0138 of K10/20 quality. The rotating edge milling cutter is an edge mill STD FP07 of ASP material (high performance steel from the powder metallurgy process) and cutting length of $19 \mathrm{~mm}$ and an $8 \mathrm{~mm}$ external diameter with 4 teeth or cutting edges.

Due to the requirements in standard UNE-EN ISO 6892-1:2017 (ISO 6892-1:2016) [35], which regulates tensile tests, it has been considered the typical tensile flat specimen shown in Figure 1.

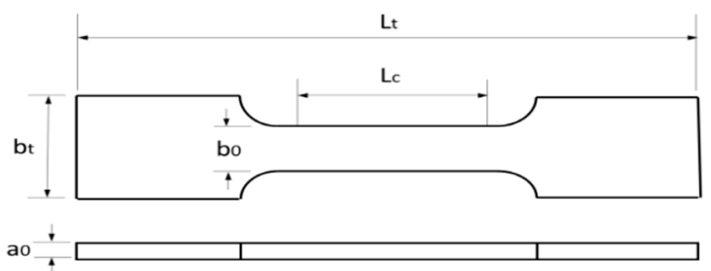

(a)

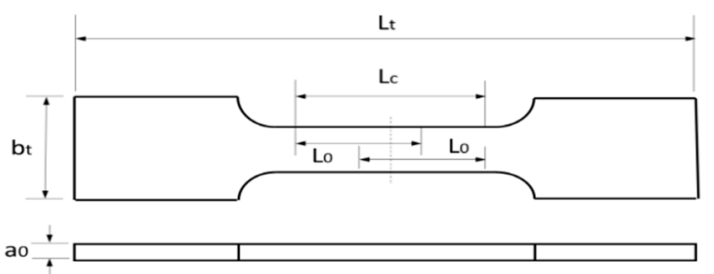

(b)

Figure 1. (a) Tensile specimen dimension; (b) Gage section and measurement distances.

Flat specimens will be used with dimensions as specified below by considering a proportional flat specimen.

$$
\begin{aligned}
& a_{0}=4 \mathrm{~mm}, b_{0}=20 \mathrm{~mm}, S_{0}=a_{0} \cdot b_{0} \\
& S_{0}=\text { original cross sectional area } \\
& L_{0}=\text { original gauge length } \\
& L_{0}=K \cdot \sqrt{S_{0}}, K=5.65 \\
& L_{0}=50 \mathrm{~mm} \\
& L_{c}=\text { paralell length } \\
& L_{c} \geq L_{o}+1.5 \cdot \sqrt{S_{0}} \\
& L_{c}=80 \mathrm{~mm} \\
& L_{t}=\text { total length }
\end{aligned}
$$

Transition radius of $12 \mathrm{~mm}$ are defined between gauge and gripping sections.

This study analyzes the influence of machining parameters on the specimens subjected to corrosion conditions. Milling machining has been selected as the machining operation to be carried out because it is said to be an essential process in the aeronautical industry. The next step consists of establishing the machining conditions that will be applied. The three primary input control parameters that will be taken into account are: cutting speed $(V c)$, depth of cut $\left(a_{p}\right)$, and feed rate $(F)$. The first two variable values will be in accordance with the cutter tool geometry and they will remain constant. The feed rate $(F)$ will be the parameter to be modified. Three values chosen from the values range provided by the manufacturer will be given. Consequently, three different study batches of specimens will be generated. Following the supplier recommendations and the milling tool characteristics, the depth of cut must be less than $7 \mathrm{~mm}$ in face milling and less than $19 \mathrm{~mm}$ in profile or edge milling. In this experience, it is established that there will be $2 \mathrm{~mm}$ of the depth of cut in the face milling and $4 \mathrm{~mm}$ in the other. Referring to cutting speed $(V c)$, due to the milling tools selected, the reference interval will be a 200 to $700 \mathrm{~m} / \mathrm{mm}$ range for face milling and a 100 to $150 \mathrm{~m} / \mathrm{mm}$ range for edge milling (manufacturer's information). Then, by taking the lowest value of cutting speed from each range, the spindle speed is determined (Equation (2)).

$$
s\left(\frac{\mathrm{rev}}{\min }\right)=\frac{V c\left(\frac{\mathrm{m}}{\min }\right) \cdot 1000\left(\frac{\mathrm{mm}}{\mathrm{m}}\right)}{\pi \cdot \mathrm{D}(\mathrm{mm})}
$$

Spindle speed in face milling (Equation (3)).

$$
s=\frac{200 \cdot 1000}{\pi \cdot 63}=1010.50
$$


Spindle speed in edge milling (Equation (4)).

$$
s=\frac{100 \cdot 1000}{\pi \cdot 8}=3978.86
$$

where

$s=$ revolution per minute of the cutter,

$V c=$ lineal cutting speed of the material in $\mathrm{m} / \mathrm{mm}$,

$D=$ diameter of the cutter in $\mathrm{mm}$

Feed rate comes from the next equation (Equation (5)).

$$
F\left(\frac{\mathrm{mm}}{\min }\right)=s\left(\frac{\mathrm{rev}}{\min }\right) \cdot Z(\text { teeth }) \cdot f z\left(\frac{\mathrm{mm}}{\text { tooth }}\right)
$$

with

$f z=$ movement per tooth of cutter in $\mathrm{mm}$

$Z=$ number of teeth of cutter

For feed per tooth, manufacturer recommendations indicate a range of 0.1 to $0.31 \mathrm{~mm}$ using the face milling tool. Experiments will be conducted taking three feed per tooth levels: $0.1 \mathrm{~mm}, 0.2 \mathrm{~mm}$, and $0.3 \mathrm{~mm}$. Therefore, considering these values on face machining, $F_{1 F}, F_{2 F}$, and $F_{3 F}$, identify the feed rate established for batch 1, batch 2, and batch 3, respectively (Equations (6)-(8)).

$$
\begin{gathered}
F_{1 F}=1010.50 \cdot 6 \cdot 0.1=606.30 \\
F_{2 F}=1010.50 \cdot 6 \cdot 0.2=1212.60 \\
F_{3 F}=1010.50 \cdot 6 \cdot 0.3=1818.90
\end{gathered}
$$

By taking the previous three feed rate levels on profile or edge machining, $F_{1 E}, F_{2 E}$, and $F_{3 E}$ are defined below (Equations (9)-(11)).

$$
\begin{gathered}
F_{1 E}=3978.86 \cdot 4 \cdot 0.06=954.93 \\
F_{2 E}=3978.86 \cdot 4 \cdot 0.065=1034.50 \\
F_{3 E}=3978.86 \cdot 4 \cdot 0.07=1114.08
\end{gathered}
$$

Machining conditions are included in Table 2.

Table 2. Machining conditions.

\begin{tabular}{ccccccc}
\hline Batch & $\begin{array}{c}\text { Face Milling } \\
\boldsymbol{V}_{\boldsymbol{c}}(\mathbf{m} / \mathbf{m i n})\end{array}$ & $\begin{array}{c}\text { Face Milling } \\
\boldsymbol{a}_{\boldsymbol{p}}(\mathbf{m m})\end{array}$ & $\begin{array}{c}\text { Face Milling } \\
\boldsymbol{F}_{\boldsymbol{F}}(\mathbf{m m} / \mathbf{m i n})\end{array}$ & $\begin{array}{c}\text { Edge Milling } \\
\boldsymbol{V}_{\boldsymbol{c}}(\mathbf{m} / \mathbf{m i n})\end{array}$ & $\begin{array}{c}\text { Edge Milling } \\
\boldsymbol{a}_{\boldsymbol{p}}(\mathbf{m m})\end{array}$ & $\begin{array}{c}\text { Edge Milling } \\
\boldsymbol{F}_{\boldsymbol{E}}(\mathbf{m m} / \mathbf{m i n})\end{array}$ \\
\hline 1 & 200 & 2 & 606.30 & 100 & 4 & 954.93 \\
2 & 200 & 2 & 1212.60 & 100 & 4 & 1034.50 \\
3 & 200 & 2 & 1818.90 & 100 & 4 & 1114.08 \\
\hline
\end{tabular}

Figure 2 shows different finish surface levels depending on the cutting conditions, which includes sample numbers 3,8 , and 12 from the batches 1,2 , and 3, respectively.

Once specimens have been machined under the cutting conditions defined in Table 2 from each batch, one sample is defined as a "control sample" and the three others will be subjected to a salt spray testing. It is widely used as a rapid method for evaluating material performance under highly corrosive conditions. 


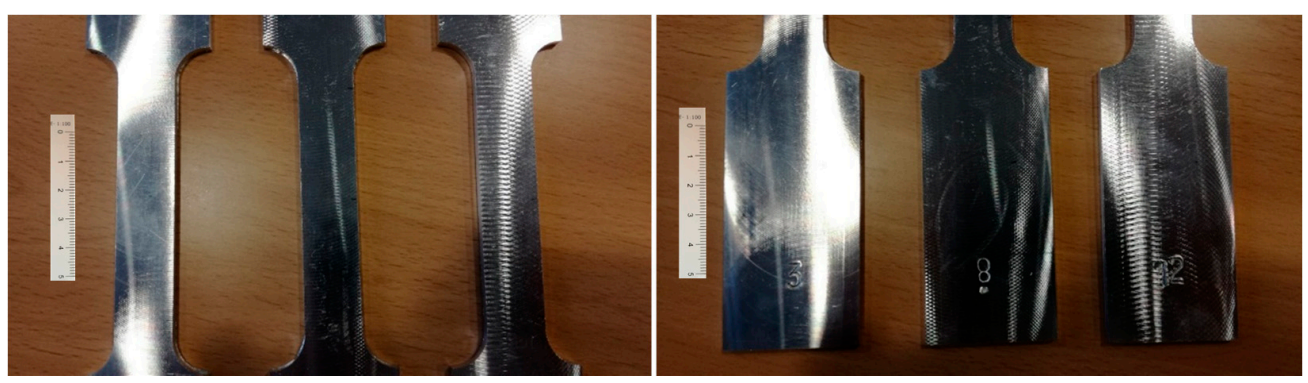

Figure 2. Machined samples from batches 1, 2, and 3 (scale bar in mm).

The aim of this experience is the evaluation of the influence of cutting parameters by using corrosion as an enhancer medium on the mechanical behavior of aluminum alloys AA7075 T651.

Previously, the application of the corrosion test, the thickness, and width of each of the specimens was measured at different points of the gauge length by calculating the average section of each specimen in that zone.

Afterward, samples are exposed to salt fog or spray that is even distributed among the samples inside a testing chamber. The salt spray (salt fog) chamber consists of a fog chamber, which is a salt solution reservoir, a supply of suitably conditioned compressed air, one or more atomizing nozzles, specimen supports, provision for heating the chamber, and necessary means of control. In this case, the apparatus is HSN400 Heraeus Votsch. Samples have been suspended between $15^{\circ}$ and $30^{\circ}$ from the vertical parallel to the principal direction of the flow of fog.

This practice provides a controlled corrosive environment by chloride solution to produce relative corrosion in the specimens exposed in the test chamber. The salt fog testing conditions applied are:

- The salt solution is a solution of sodium chloride dissolved in distilled water with $(50 \pm 5) \mathrm{g} / \mathrm{L}$ concentration

- The exposure zone of the salt spray chamber has been maintained at $35^{\circ} \mathrm{C} \pm 2{ }^{\circ} \mathrm{C}$

- $\quad$ The $\mathrm{pH}$ of the salt solution is such that, when atomized to $35^{\circ} \mathrm{C}$, the collected solution will be in a pH range between 6.5 to 7.2 . The registered $\mathrm{pH}$ values have approached 6.5 and were measured by $\mathrm{pH}$ test paper.

- $\quad$ Spraying has been controlled by the average collected speed of atomized solution in minimum periods of $24 \mathrm{~h}$. The spraying range in a horizontal manifold of $80 \mathrm{~cm}^{2}$ must be 1 to $2.5 \mathrm{~mL} / \mathrm{h}$. The volumes collected every $24 \mathrm{~h}$ have come close to $50 \mathrm{~mL}$. Lastly, the period of exposure reached $168 \mathrm{~h}$.

At the end of the test, specimens have been carefully removed and dipped in distilled water to remove salt and deposits from their surface and then they are immediately dried.

Once dried, they are wrapped in cellulose with desiccants. They will be kept in a watertight compartment until the next step. Figure $3 a-c$ show the effect of the corrosive process on the samples tested.

Along with finished previous stages, the machined process, and the salt spray test, specimens will be subjected to tensile tests. They will provide information about the strength or their mechanical behavior.

The equipment used is a universal testing machine for tensile/compression/flexure 1 to $500 \mathrm{kN}$, ME 405 SERVOSIS, controlled by PCD2K test software (version 1.2) [36] that will give a test report with the required calculations and test results, data, and graphics. This testing machine works with two load cells of which the $100 \mathrm{kN}$ one will be used in this experiment.

Tensile tests are performed at a room temperature range between $10^{\circ} \mathrm{C}$ and $35{ }^{\circ} \mathrm{C}$ (Figure 4). The sample dimensions have been described before. They are proportional with gage length, rectangular cross-sectional area, and soft transition radius connecting gage and gripping sections. Elongation at the break will be evaluated by measuring the length increase between the initial marks of the samples. The displacement speed of wedge grips is fixed in $1 \mathrm{~mm} / \mathrm{min}$ [35]. 


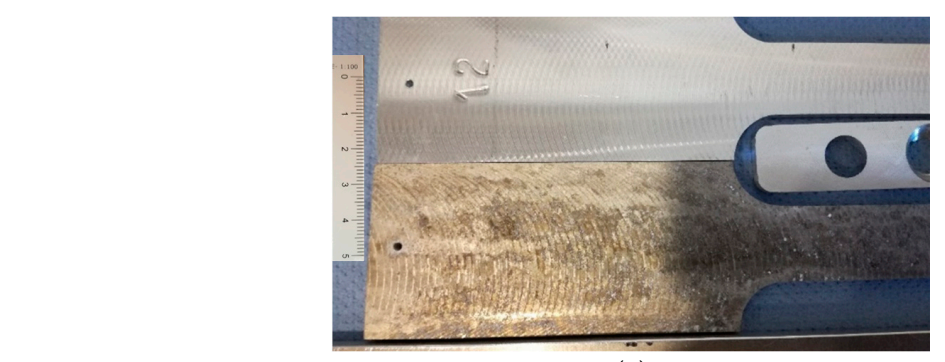

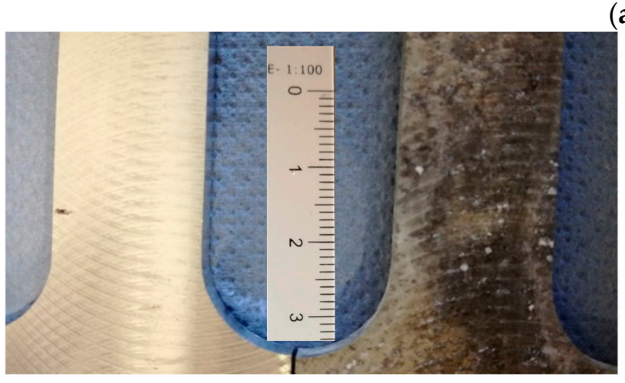

(b)

(a)

Figure 3. (a-c) Subject and no subject to corrosion specimens (scale bar in $\mathrm{mm}$ ).

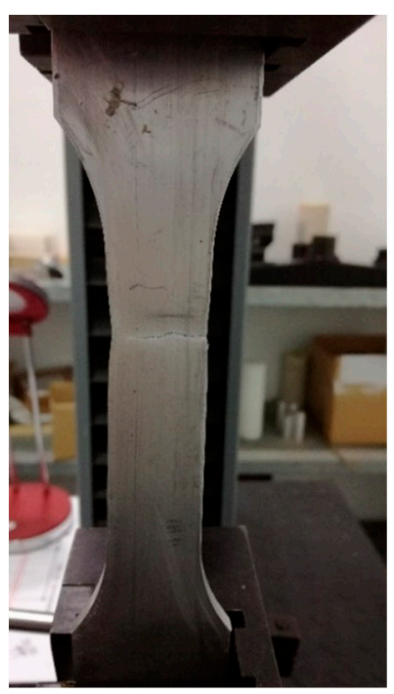

(a)

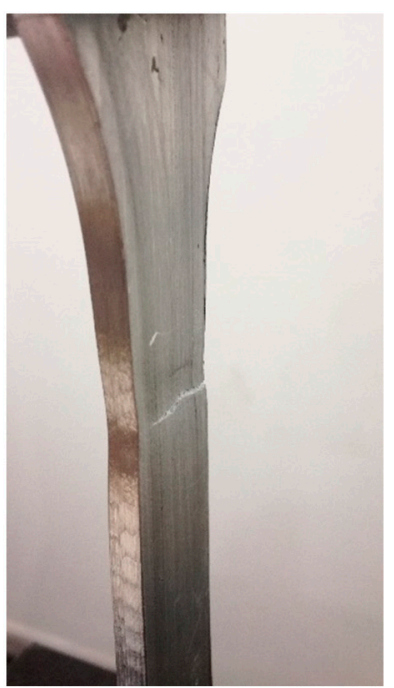

(b)

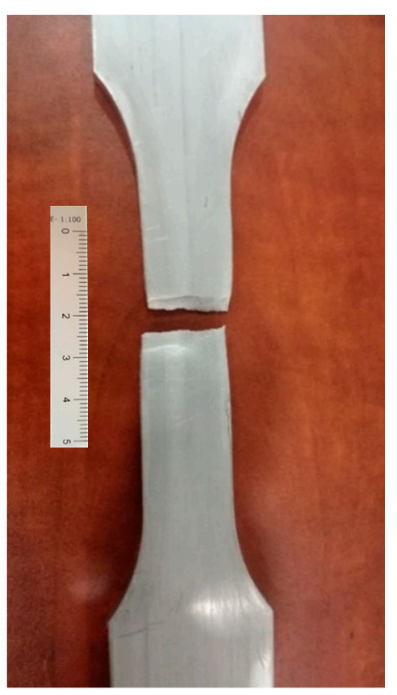

(c)

Figure 4. (a,b) Sample during the test; (c) Sample after the test (scale bar in $\mathrm{mm}$ ).

The tensile force is recorded as a function of the increase in gage length. Such plots of the tensile force versus tensile elongation would be normalized to the Stress-Strain curve.

- $\quad$ Engineering stress: $\sigma=\frac{F}{S_{0}}$ where $F$ is the tensile force and $S_{0}$ is the initial cross-sectional area of the gage section.

- Nominal engineering strain: $\varepsilon_{n}=\frac{\left(L_{u}-L_{0}\right)}{L_{0}}$ where $L_{0}$ is the initial gage length and $L_{u}$ is the final one.

Taking this curve as a starting point, the value of the conventional elastic limit is determined by applying a linear regression method to the registers of the proportional elastic zone of the curve. Due to the need of a high goodness of fit of the data to the mathematical relationship, the correlation coefficient, $R^{2}$, will not be less than 0.999 . Once this curve has been adjusted again to the estimated deformation of $0.2 \%$, the cut point of this new curve with the initial curve adjusted will provide the value of the elastic limit corresponding to the material tested $\left(\sigma_{e}\right)$ (Figure 5). Last instant of the tensile test is delimited by tensile strength $\sigma_{R}$. 
Regarding the elongation at break, $A$, it will be calculated from the next expression.

$$
A=\frac{L_{u}-L_{0}}{L_{0}} \cdot 100
$$

with $L_{0}=$ initial length and $L_{u}=$ length after a break. Measuring $L_{u}$ is especially critical because it requires a careful approach to ensure the best contact between both parts. This distance has been measured using a digital Vernier caliper of precision $0.01 \mathrm{~mm}$.

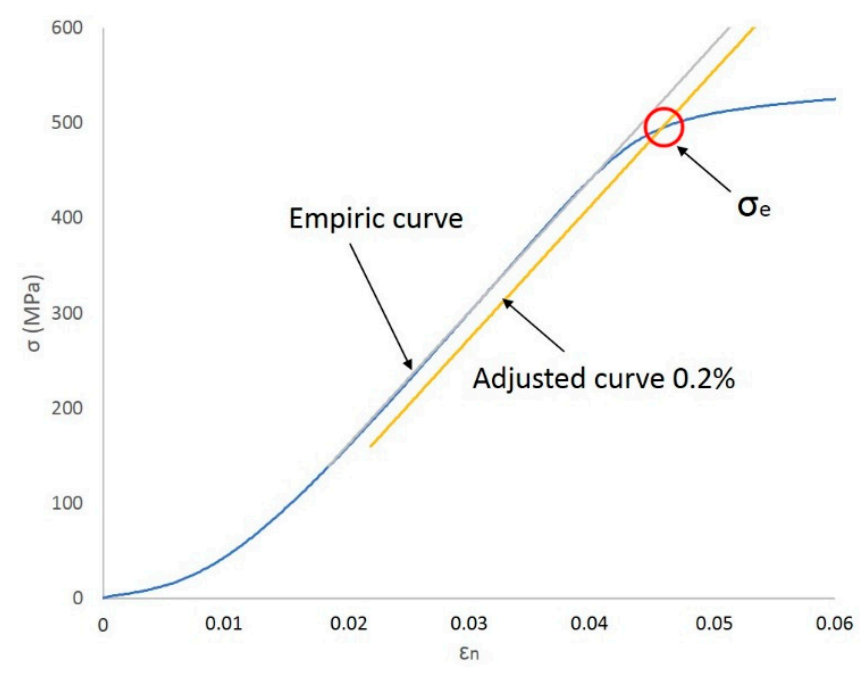

Figure 5. Elastic limit in an adjusted curve.

\section{Results and Discussion}

Once the tensile tests have been done on both types of flat specimens considered, the denominated "control samples" and ones that have been previously subjected to a corrosive environment (specifically identified with the letter " $\mathrm{C}$ ") as well as the parameter values that characterize their mechanical behavior, yield strength, tensile strength, and elongation are analyzed.

Table 3 presents the set of results obtained.

Table 3. Testing and measurement results.

\begin{tabular}{ccccc}
\hline Specimen & Section $\left.\mathbf{( m m}^{\mathbf{2}}\right)$ & Yield Strength $\mathbf{0 . 2} \% \boldsymbol{\sigma}_{\boldsymbol{e}} \mathbf{( M P a )}$ & Tensile Strength $\sigma_{\boldsymbol{R}} \mathbf{( M P a )}$ & Elongation at Break $\boldsymbol{A} \mathbf{( \% )}$ \\
\hline 1C & 80.80 & 498.50 & 557.75 & 11.18 \\
2C & 79.41 & 495.11 & 554.36 & 13.06 \\
3 & 79.69 & 497.90 & 557.90 & 14.32 \\
4C & 82.16 & 481.94 & 548.30 & 8.18 \\
5C & 79.35 & 487.87 & 553.37 & 10.04 \\
6C & 80.72 & 492.02 & 553.73 & 9.72 \\
7C & 81.48 & 480.32 & 546.70 & 10.40 \\
8 & 80.34 & 486.37 & 547.49 & 12.80 \\
9C & 82.76 & 481.65 & 542.09 & 10.74 \\
10C & 82.92 & 486.11 & 554.46 & 12.76 \\
11C & 80.81 & 483.39 & 536.72 & 11.12 \\
12 & 80.24 & 488.20 & 556.63 & 11.50 \\
\hline
\end{tabular}

From these results, it is possible to do comparative evaluations between the controlled parameters on each specimen by considering the different variables on influence.

- Kind of specimen

- Corrosive action

- Milling machining conditions 
Due to the specimens' dimensions, it is necessary to calculate not only the absolute values of the mechanical parameters (elastic limit, tensile strength, and elongation at break) but the relative values of these three parameters, according to each specimen cross section $\left(S_{0}\right)$. Thus, the next tables and graphics show results from the evaluation of yield strength and yield strength/section relation (Table 4, Figure 6), tensile strength and tensile strength/section relation (Table 5, Figure 7), elongation to break and elongation at break/section relation (Table 6, Figure 8), and relation tensile strength/elongation at break (Table 7, Figure 9).

Table 4. Yield strength and yield strength/section relation values per specimen and Medium values.

\begin{tabular}{|c|c|c|}
\hline \multirow{2}{*}{ Specimen } & Yield Strength & Yield Strength/Section \\
\hline & (MPa) & $\left(\mathrm{MPa} / \mathrm{mm}^{2}\right)$ \\
\hline 3 & 497.90 & 6.25 \\
\hline 8 & 486.37 & 6.05 \\
\hline 12 & 488.20 & 6.08 \\
\hline Medium value a $(3,8,12)$ & 490.82 & 6.13 \\
\hline Standard deviation & 6.20 & 0.11 \\
\hline $1 \mathrm{C}$ & 498.50 & 6.17 \\
\hline $2 \mathrm{C}$ & 495.11 & 6.23 \\
\hline $4 \mathrm{C}$ & 481.94 & 5.87 \\
\hline Medium value $b(1 C, 2 C, 4 C)$ & 491.85 & 6.09 \\
\hline Standard deviation & 8.75 & 0.19 \\
\hline $5 \mathrm{C}$ & 487.87 & 6.15 \\
\hline $6 \mathrm{C}$ & 492.02 & 6.09 \\
\hline $7 \mathrm{C}$ & 480.32 & 5.89 \\
\hline Medium value $c(5 C, 6 C, 7 C)$ & 486.74 & 6.05 \\
\hline Standard deviation & 5.93 & 0.14 \\
\hline $9 \mathrm{C}$ & 481.65 & 5.82 \\
\hline $10 \mathrm{C}$ & 486.11 & 5.86 \\
\hline $11 \mathrm{C}$ & 483.39 & 5.98 \\
\hline Medium value d $(9 \mathrm{C}, 10 \mathrm{C}, 11 \mathrm{C})$ & 483.72 & 5.89 \\
\hline Standard deviation & 2.25 & 0.08 \\
\hline Corrosion total medium value $(\mathrm{MVt}=(\mathrm{MVb}+\mathrm{MVc}+\mathrm{MVd}) / 3)$ & 487.43 & 6.01 \\
\hline Standard deviation & 4.11 & 0.11 \\
\hline
\end{tabular}

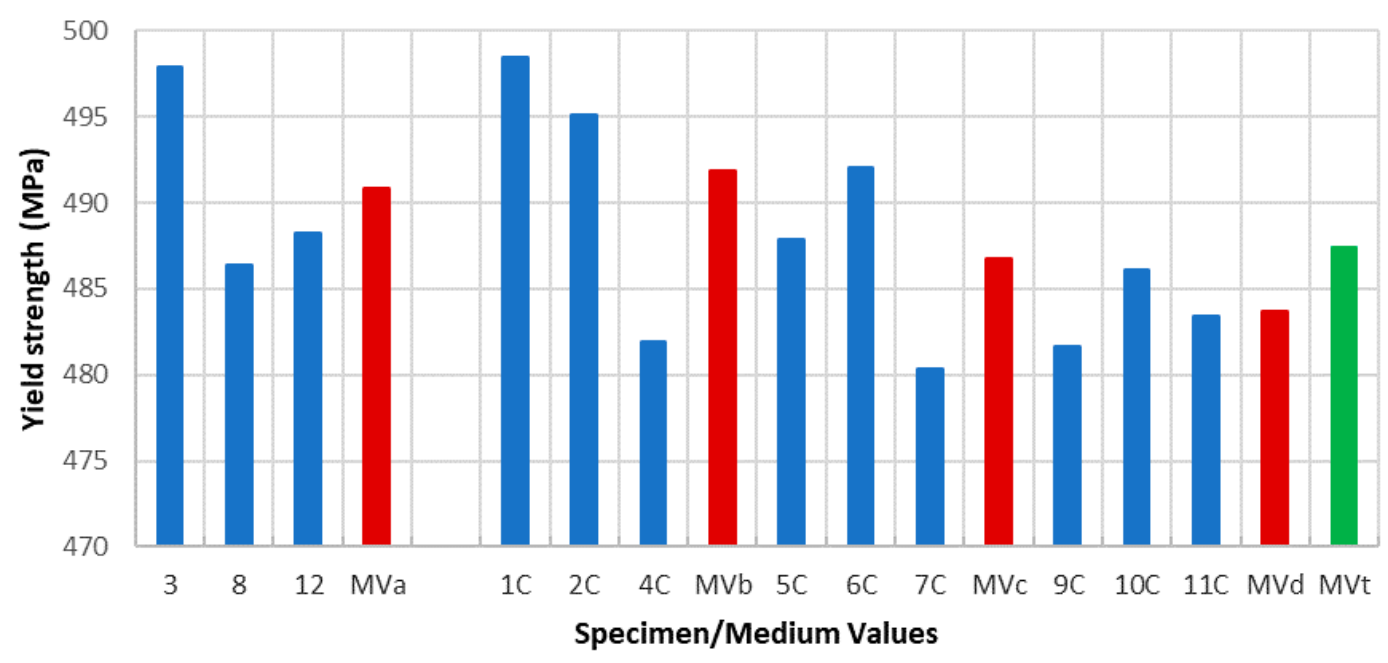

Figure 6. Yield strength vs. specimen and medium values. 
Table 5. Tensile strength and tensile strength/section relation values per specimen and medium values.

\begin{tabular}{|c|c|c|}
\hline \multirow{2}{*}{ Specimen } & Tensile Strength & Tensile Strength/Section \\
\hline & (MPa) & $\left(\mathrm{MPa} / \mathrm{mm}^{2}\right)$ \\
\hline 3 & 557.90 & 7.00 \\
\hline 8 & 547.49 & 6.81 \\
\hline 12 & 556.63 & 6.94 \\
\hline Medium Value a $(3,8,12)$ & 554.01 & 6.92 \\
\hline Standard deviation & 5.68 & 0.10 \\
\hline $1 \mathrm{C}$ & 557.75 & 6.90 \\
\hline $2 \mathrm{C}$ & 554.36 & 6.98 \\
\hline $4 \mathrm{C}$ & 548.30 & 6.67 \\
\hline Medium value $b(1 C, 2 C, 4 C)$ & 553.47 & 6.85 \\
\hline Standard deviation & 4.79 & 0.16 \\
\hline $5 \mathrm{C}$ & 553.37 & 6.97 \\
\hline $6 \mathrm{C}$ & 553.73 & 6.86 \\
\hline $7 \mathrm{C}$ & 546.70 & 6.71 \\
\hline Medium value $c(5 C, 6 C, 7 C)$ & 551.27 & 6.81 \\
\hline Standard deviation & 3.96 & 0.13 \\
\hline 9C & 542.09 & 6.55 \\
\hline $10 \mathrm{C}$ & 554.46 & 6.67 \\
\hline $11 \mathrm{C}$ & 536.72 & 6.64 \\
\hline Medium value d (9C, 10C, 11C) & 544.42 & 6.94 \\
\hline Standard deviation & 9.10 & 0.06 \\
\hline $\begin{array}{l}\text { Corrosion total medium value } \\
(\mathrm{MVt}=(\mathrm{MVb}+\mathrm{MVc}+\mathrm{MVd}) / 3)\end{array}$ & 549.72 & 6.77 \\
\hline Standard deviation & 4.72 & 0.07 \\
\hline
\end{tabular}

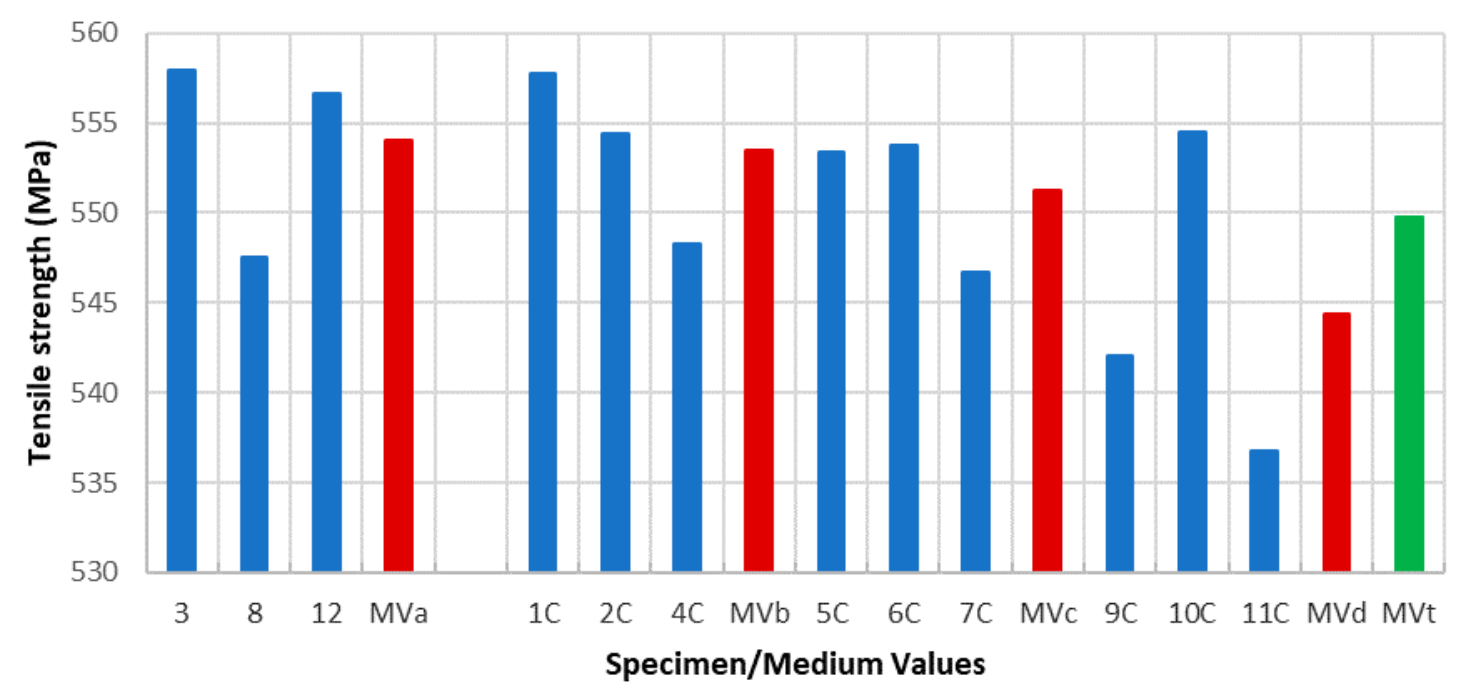

Figure 7. Tensile strength vs. specimen and medium values. 
Table 6. Elongation at break and elongation at break/section relation values per specimen and medium values.

\begin{tabular}{|c|c|c|}
\hline \multirow{2}{*}{ Specimen } & Elongation & Elongation/Section \\
\hline & $(\%)$ & $\left(\% / \mathrm{mm}^{2}\right)$ \\
\hline 3 & 14.32 & 0.18 \\
\hline 8 & 12.80 & 0.16 \\
\hline 12 & 11.50 & 0.14 \\
\hline Medium value a $(3,8,12)$ & 12.87 & 0.16 \\
\hline Standard deviation & 1.41 & 0.02 \\
\hline $1 \mathrm{C}$ & 11.18 & 0.14 \\
\hline $2 \mathrm{C}$ & 13.06 & 0.16 \\
\hline $4 \mathrm{C}$ & 8.18 & 0.10 \\
\hline Medium value $b(1 C, 2 C, 4 C)$ & 10.81 & 0.13 \\
\hline Standard deviation & 2.46 & 0.03 \\
\hline $5 \mathrm{C}$ & 10.04 & 0.13 \\
\hline $6 \mathrm{C}$ & 9.72 & 0.12 \\
\hline $7 \mathrm{C}$ & 10.40 & 0.13 \\
\hline Medium value $c(5 C, 6 C, 7 C)$ & 10.05 & 0.12 \\
\hline Standard deviation & 0.34 & 0.01 \\
\hline $9 \mathrm{C}$ & 10.74 & 0.13 \\
\hline $10 \mathrm{C}$ & 12.76 & 0.15 \\
\hline $11 \mathrm{C}$ & 11.12 & 0.14 \\
\hline Medium value d $(9 \mathrm{C}, 10 \mathrm{C}, 11 \mathrm{C})$ & 11.54 & 0.14 \\
\hline Standard deviation & 1.07 & 0.01 \\
\hline $\begin{array}{l}\text { Corrosion total medium value } \\
(\mathrm{MVt}=(\mathrm{MVb}+\mathrm{MVc}+\mathrm{MVd}) / 3)\end{array}$ & 10.80 & 0.13 \\
\hline Standard deviation & 0.75 & 0.01 \\
\hline
\end{tabular}

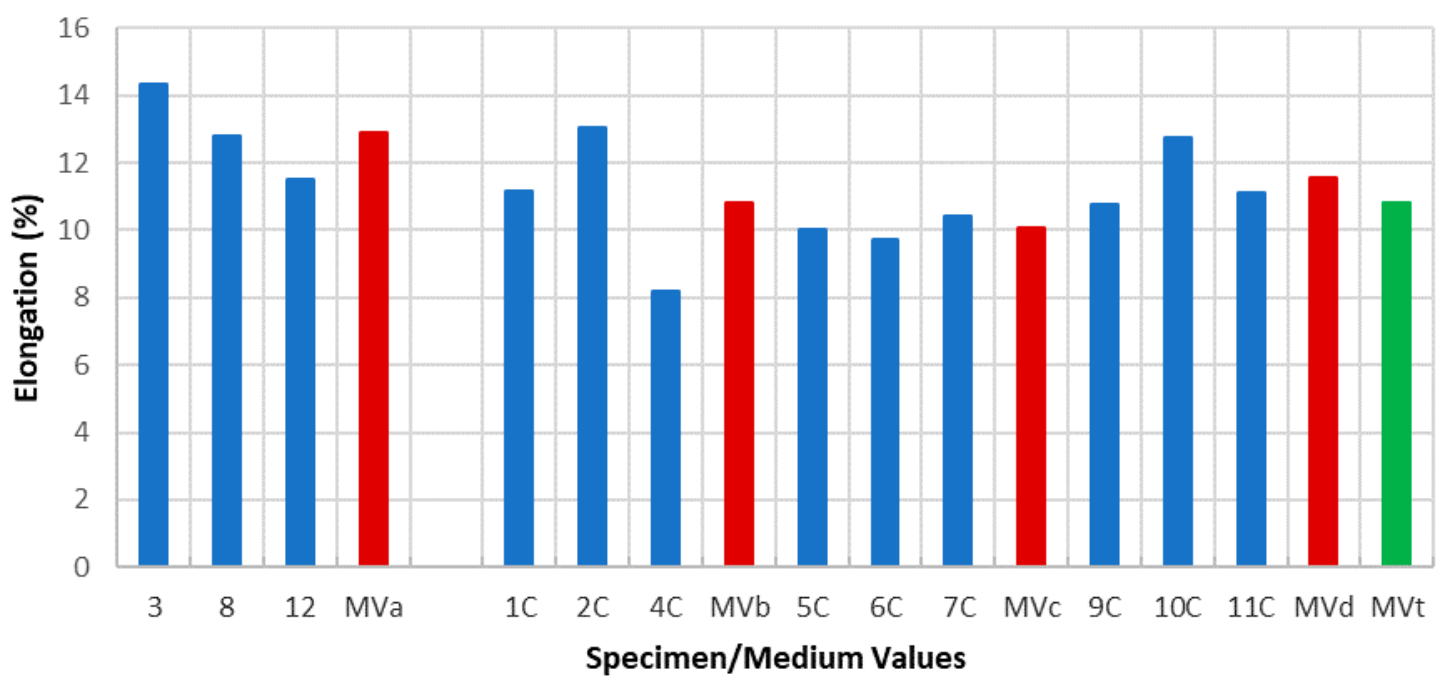

Figure 8. Elongation vs. specimen and medium values. 
Table 7. Tensile strength/elongation relation values per specimen and medium values.

\begin{tabular}{cc}
\hline Specimen & Tensile Strength/Elongation (MPa/\%) \\
\hline 3 & 38.96 \\
8 & 42.77 \\
12 & 48.40 \\
Medium value a $(3,8,12)$ & 43.38 \\
Standard deviation & 4.75 \\
1C & 49.89 \\
2C & 42.45 \\
4C & 67.03 \\
Medium value b (1C, 2C, 4C) & 53.12 \\
Standard deviation & 12.60 \\
6C & 55.12 \\
7C & 56.97 \\
9C & 52.57 \\
11C & 54.88 \\
Medium value c (5C, 6C, 7C) & 2.21 \\
Standard deviation & 50.47 \\
Corrosion total medium value & 43.45 \\
Standard deviation & 48.27 \\
Standard deviation & 47.40 \\
Medium & 3.59 \\
\hline MVb & 51.80 \\
\hline
\end{tabular}

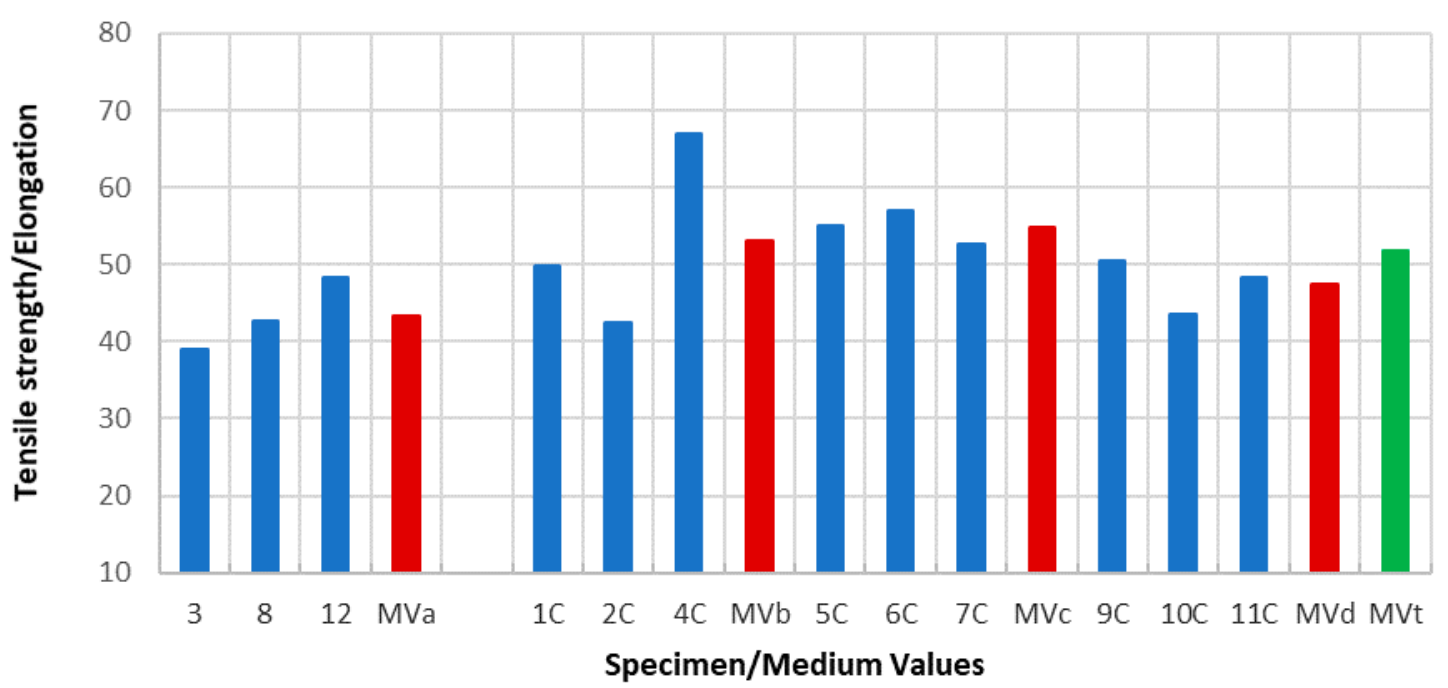

Figure 9. Tensile strength/elongation relation values and medium values.

Data shown in Tables 4-7 and Figures 6-9 express those results relative to specimens not subjected to a corrosive environment ("control specimens") and the three milling machined conditions (specimens 3, 8, and 12). In addition, medium values have been calculated and identified as MVa (medium value a). On the other side, Specimens 1C, 2C, and 4C belongs to batch 1 and they have been exposed to salt fog. Its corresponding medium value is $\mathrm{MVb}$. Specimens from batch 2 including 5C, 6C, and 7C have suffered a corrosive attack. In this case, it is assigned the medium value MVc. The three next specimens include 9C, 10C, and 11C from batch 3 and under corrosive action present a medium value identified by MVd. Eventually, the last column shows the medium value of the three previous medium values from the batches of samples subjected to corrosion conditions that include $\mathrm{MVb}, \mathrm{MVc}$, and MVd. This parameter, MVt, represents the total medium value corresponding to the behavior of the studied variable. 
Establishing relations between the samples areas and the machining parameters considered allows us to make a more accurate evaluation of how their mechanical behavior is affected by the machining conditions. According to standard deviations included in Tables 4-7, the results show a reduced dispersion when cross sections are taken into account. Tables 8 and 9 and Figures 10 and 11 show the percentage variations of the elastic limit and the tensile strength. As shown, both percentages do not exceed the $4.6 \%$ between extreme values from each batch. Concretely, the reduced difference that both parameters present in batch 2 may indicate that, for this combination of machining parameters, the variation of the micro-geometry does not significantly affect the mechanical properties considered (tensile strength and elastic limit).

Table 8. Yield strength/section values per specimen and medium values vs. batch.

\begin{tabular}{cccc}
\hline Batch & $\begin{array}{c}\text { Yield Strength/Section } \\
\text { Specimen without Corrosion } \\
\mathbf{( 1 )}\left(\mathbf{M P a} / \mathbf{m m}^{\mathbf{2}}\right)\end{array}$ & $\begin{array}{c}\text { Yield Strength/Section } \\
\text { Medium Values with } \\
\text { Corrosion (2) (MPa/mm } \mathbf{~})\end{array}$ & (1)/(2) (\%) \\
\hline 1 & $6.25($ specimen 3) & $6.09(\mathrm{MVb})$ & 2.59 \\
2 & $6.05($ specimen 8$)$ & $6.04(\mathrm{MVc})$ & 0.13 \\
3 & $6.08($ specimen 12) & $5.89(\mathrm{MVd})$ & 3.33 \\
Extreme values variation (\%) & 3.21 & 3.43 & \\
\hline
\end{tabular}

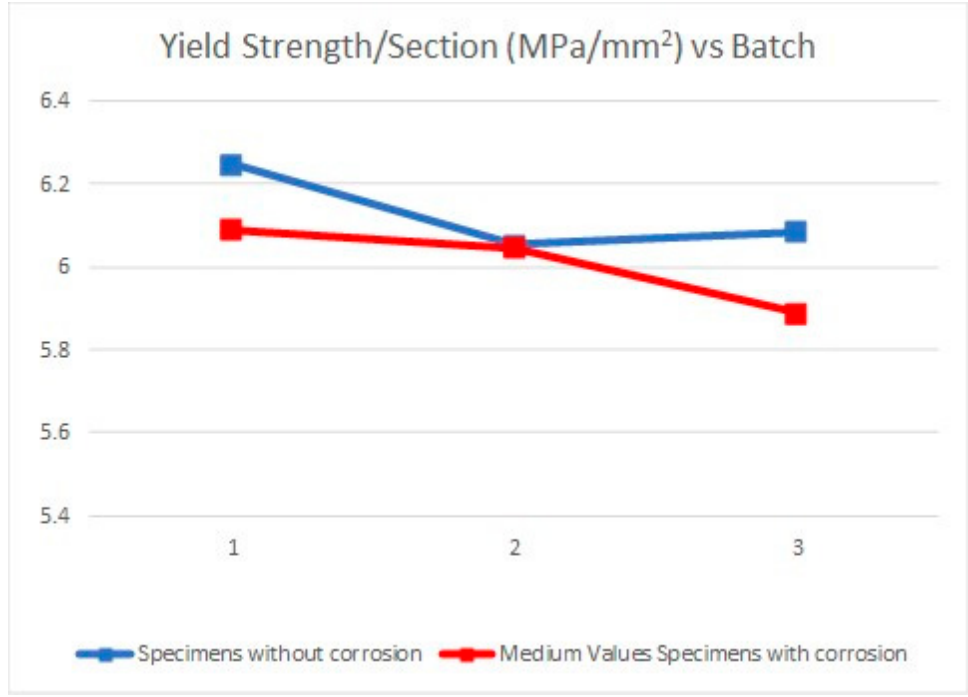

Figure 10. Yield strength/Section vs. Batch.

Table 9. Tensile strength/Section values per specimen and Medium values vs. Batch.

\begin{tabular}{cccc}
\hline Batch & $\begin{array}{c}\text { Tensile Strength/Section } \\
\text { Specimen without } \\
\text { Corrosion (1) } \mathbf{( M P a / \mathbf { m m } ^ { 2 } )}\end{array}$ & $\begin{array}{c}\text { Tensile Strength/Section } \\
\text { Medium Values with } \\
\text { Corrosion (2) }\left(\mathbf{M P a} / \mathbf{m m}^{2}\right)\end{array}$ & (1)/(2) (\%) \\
\hline 1 & $7.00($ specimen 3) & $6.85(\mathrm{MVb})$ & 2.17 \\
2 & 6.81 (specimen 8) & $6.85(\mathrm{MVc})$ & -0.48 \\
3 & 6.94 (specimen 12) & $6.63(\mathrm{MVd})$ & 4.69 \\
Extreme values variation (\%) & 2.73 & 3.41 & \\
\hline
\end{tabular}

In the opposite, the elongation at break is strongly influenced by the machining process and the activator effect of the corrosion on the surface roughness of each specimen (Table 10, Figure 12). In this sense, the increasing roughness level dependent on the machining conditions $\left(R_{a 1}<R_{a 2}<R_{a 3}\right)$ prompts a fragility increase and consequently a lesser percentage elongation. Likewise, a similar situation is presented in specimens exposed to a corrosive environment and machined under cutting conditions 
identified as batch 1 and batch 2 . In this case, not only is there a decrease on the percentage elongation but that decrease is very significant. Furthermore, an important difference appears with the percentage elongation of the "control specimen" being $33.97 \%$ in batch 1 and $27.60 \%$ in batch 2 . These results show how the Aluminum 7075 ductility can be affected by the machining conditions applied.

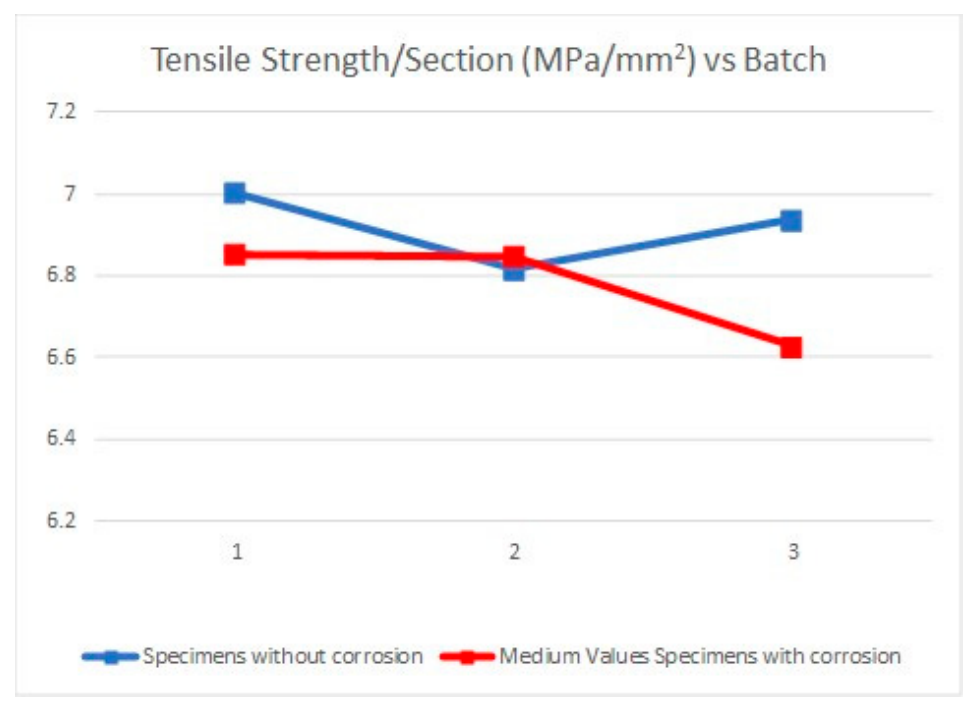

Figure 11. Tensile strength/Section vs. Batch.

Table 10. Elongation/Section values per specimen and Medium values vs. Batch.

\begin{tabular}{|c|c|c|c|}
\hline Batch & $\begin{array}{c}\text { Elongation/Section } \\
\text { Specimen without } \\
\text { Corrosion }(1)\left(\% / \mathrm{mm}^{2}\right)\end{array}$ & $\begin{array}{c}\text { Elongation/Section } \\
\text { Medium Values with } \\
\text { Corrosion (2) }\left(\% / \mathrm{mm}^{2}\right)\end{array}$ & $(1) /(2)(\%)$ \\
\hline 1 & 0.18 (specimen 3 ) & $0.13 \mathrm{MVb}$ & 33.97 \\
\hline 2 & 0.16 (specimen 8$)$ & $0.12 \mathrm{MVc}$ & 27.60 \\
\hline 3 & 0.14 (specimen 12) & $0.14 \mathrm{MVd}$ & 2.06 \\
\hline Extreme values variation (\%) & 25.38 & 12.46 & \\
\hline
\end{tabular}

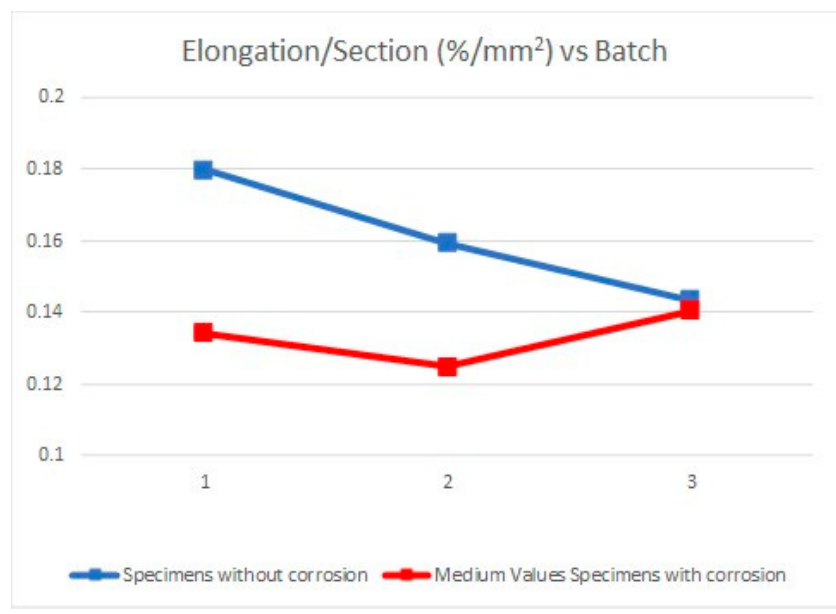

Figure 12. Elongation/Section vs. Batch.

However, batch 3 does not present the same behavior than batches described before. A similar comparison between values from the "control specimen" and specimens under corrosion conditions produces a result of $2.06 \%$. The amount is especially insignificant compared to the results obtained with batches 1 and 2. Analyzing these results, it can be deduced that the combination of cutting 
depth, feed per teeth, and cutting speed in batch 3 reduces strongly the stimulator effect of the corrosion in relation to its fragility. These are not, nevertheless, the suitable machining conditions because the higher increase of the feed per tooth produces a rise in surface roughness and a fall in the percentage elongation.

Taking absolute values (without relation to cross sections), the conclusions deduced from the study of each one of the parameters contemplated in the different conditions of the test reveals that, in the case of the elastic limit, the similar behavior under different machining conditions and the average value obtained from the specimens without a corrosive action is $490.82 \mathrm{MPa}$. Therefore, we can establish this value as the elastic limit value of the material under study. For the samples subjected to a corrosive attack, the evolution of the average values of the yield strength is such that the result from batch 1, 491.85 MPa, is insignificant while it is demonstrated that a higher influence on the value of the elastic limit for the samples from batches 2 and 3. It can be observed as a downward trend of this evolution. The result is $486.74 \mathrm{MPa}$, which is the value of batch 2, and $483.72 \mathrm{MPa}$, which is the value for batch 3 . This tendency is evident in the total average from the set of specimens under corrosion. This parameter (MVt) offers the value of $487.43 \mathrm{MPa}$.

Regarding the tensile strength, the evolution presents a similar aspect than the previous case. The average value of samples 3, 8, and 12 is $554.01 \mathrm{MPa}$ while those one from the batches 1, 2, and 3 are $553.47 \mathrm{MPa}$, 551.27 MPa, and 554.42 MPa, respectively, which offers an average value of $549.72 \mathrm{MPa}$. It can be seen that a similar downward trend of the tensile strength occurs, according to the three different machined conditions.

Referring to elongation at break, results evidence a greater difference of the behavior of the samples subjected to corrosion tests. The summarized results according to the medium values obtained are: Average value of elongation at break for, without corrosion, $12.87 \%$ (similar to usual values in alloys of this type), specimens from corrosion tests and batch 1, 10.81\%, batch 2, 10.05\%, and batch 3, $11.54 \%$, resulting in a total medium value of $10.80 \%$. Overall, the decrease in the value of the percentage of elongation is even greater than in the two previous parameters contemplated.

Due to the tensile strength and elongation at break having been obtained by procedures of different empirical nature, mechanical testing in the first case and geometrical measurements in the second one establish the level of reliability offered by the two methods employed based on a relation that has been established between them with an eminently qualitative character. Since the reduction of the values of elongation is greater than that presented by the tensile strength values about the set of specimens subjected to corrosion, the medium values obtained for the considered relationship must be higher in the three series studied under these conditions (43.38 of MVa, against values of $53.12 \mathrm{of} \mathrm{MVb}$, 54.88 of MVc, 47.40 of MVd and, therefore, 51.80 of MVt).

\section{Conclusions}

This work is supposed to present a new approach in the study of the response of the AA7075 T651 alloy, which is widely used in the aeronautic industry, to different mechanical and chemical actions such as milling machining and the corrosion process. In this sense, this work deals with a study field where it hardly exists in the literature.

Considering typical processes used in aeronautics, dry face milling has been selected as the machining operation to perform on the flat samples (different combinations by fixing cutting speed and depth of cut and modifying the feed rate). The corrosive environment has been obtained by means of a salt fog chamber.

Different specific combinations of geometrical and technological cutting parameters are applied on flat specimens, which have been divided in two study groups. Samples belong to the second group and have been additionally exposed to a corrosive environment.

Based on the results obtained, it can be clearly seen as a relevant influence of both processes. On the one hand, whatever combination of milling parameters is applied, samples without a corrosion effect show an insignificant variation of their mechanical property values $(2.37 \%$ in tensile strength 
and $1.90 \%$ in yield strength). However, the elongation at break presents a great reduction $(24.5 \%)$ that varies inversely with the feed rate increase. Consequently, a higher feed rate results in a greater fragility of the material.

On the other hand, analyzing specimens machined and subjected to corrosion, results reveal that this phenomenon provokes a strong influence on the elongation at break. The elongation reduction follows a similar tendency with respect to samples without corrosion, but these samples present an evident greater fragility with an average elongation of $10.80 \%$ in comparison to the $12.87 \%$ of the first ones. Therefore, it produced an additional significant reduction of the $19.17 \%$.

It is necessary to point out that all these observations are only valid within the tested range of milling parameters.

Author Contributions: Conceptualization and Investigation, M.J.M., F.M. and M.J.C. Methodology, M.J.M., F.M., M.J.C. and G.C. Resources, M.J.H. Formal Analysis and Writing-Review \& Editing, M.J.M. Writing-Original Draft Preparation, M.J.M. and F.M. Visualization and Supervision, F.M.

Funding: This research received no external funding.

Acknowledgments: The authors want to thank the University of Malaga-Andalucia Tech, International Campus of Excellence, for its financial support of this paper.

Conflicts of Interest: The authors declare no conflict of interest.

\section{References}

1. Ezugwu, E.; Bonney, J.; Yamane, Y. An overview of the machinability of aeroengine alloys. J. Mater. Process. Technol. 2003, 134, 233-253. [CrossRef]

2. Dursun, T.; Soutis, C. Recent developments in advanced aircraft aluminum alloys. Mater. Des. 2014, 56, 862-871. [CrossRef]

3. UNE-EN 573-3:2014. Aluminium and Aluminium Alloys-Chemical Composition and Form of Wrought Products_Part 1: Numerical Designation System; AENOR: Madrid, Spain, 2014.

4. Sahoo, A.K.; Pradhan, S.; Rout, A.K. Development and machinability assessment in turning Al/SiCp-metal matrix composite with multilayer coated carbide insert using Taguchi and statistical techniques. Arch. Civ. Mech. Eng. 2013, 13, 27-35. [CrossRef]

5. Charles, J.A.; Crane, F.A.A.; Furness, J.A.G. 15-Materials for airframes. In Selection and Use of Engineering Materials, 3rd ed.; Butterworth-Heinemann: Oxford, UK, 1997; pp. 227-255.

6. Hinrichsen, J.; Bautista, C. The challenge of reducing both airframe weight and manufacturing cost. Air Space Eur. 2001, 3, 119-121. [CrossRef]

7. De Agustina, B.; Bernal, C.; Camacho, A.M.; Rubio, E.M. Experimental analysis of the cutting forces obtained in dry turning processes of UNS A97075 Aluminum alloys. Procedia Eng. 2013, 63, 694-699. [CrossRef]

8. Gokkaya, $\mathrm{H}$. The effects of machining parameters on cutting forces, surface roughness, built-up edge (BUE) and built-up layer (BUL) during machining AA2014 (T4) alloy. J. Mech. Eng. 2010, 56, 584-593.

9. De Agustina, B.; Rubio, E.M.; Sebastián, M.A. Surface roughness predictive model of UNS A97075 aluminum pieces obtained by dry turning tests based on the cutting forces. Appl. Mech. Mater. 2012, 217-219, 1628-1635. [CrossRef]

10. Trujillo, F.J.; Sevilla, L.; Marcos, M. Cutting speed-feed coupled experimental model for geometric deviations in the dry turning of UNS A97075 Al-Zn alloys. Adv. Mech. Eng. 2014, 1, 1-11. [CrossRef]

11. Salguero, J.; Batista, M.; Calamaz, M.; Girot, F.; Marcos, M. Cutting forces parametric model for the dry highspeed contour milling of aerospace aluminum alloys. Procedia Eng. 2013, 63, 735-742. [CrossRef]

12. Baek, D.K.; Ko, T.J.; Kim, H.S. Optimization of feedrate in a face milling operation using a surface roughness model. Int. J. Mach. Tools Manuf. 2001, 41, 451-462. [CrossRef]

13. Salguero Gómez, J. Analysis, Evaluation and Proposals for Performance Enhancing in Highspeed Machining of Aeronautical Aluminum Alloys. Ph.D. Thesis, University of Cadiz, Cadiz, Spain, 2013.

14. Cai, X.J.; Ming, W.W.; Chen, M. Surface integrity analysis on high speed end milling of 7075 aluminium alloy. Adv. Mater. Res. 2012, 426, 321-324. [CrossRef]

15. Ammula, S.C.; Guo, Y.B. Surface integrity of Al 7050-T7451 and Al 6061-T651 induced by high speed milling. J. Aerosp. 2005. [CrossRef] 
16. Sreejith, P.S. Machining of 6061 aluminium alloy with MQL, dry and flooded lubricant conditions. Mater. Lett. 2008, 62, 276-278. [CrossRef]

17. Shokrani, A.; Dhokia, V.; Newman, S.T. Environmentally conscious machining of difficult-to-machine materials with regard to cutting fluids. Int. J. Mach. Tools Manuf. 2012, 57, 83-101. [CrossRef]

18. Itoigawa, F.; Childs, T.H.C.; Nakamura, T.; Belluco, W. Effects and mechanisms in minimal quantity lubrication machining of an aluminum alloy. Wear 2006, 260, 339-344. [CrossRef]

19. Chen, L.; Hsieh, C.-C.; Wetherbee, J.; Yang, C.-L. Characteristics and treatability of oil-bearing wastes from aluminum alloy machining operations. J. Hazard. Mater. 2008, 152, 1220-1228. [CrossRef] [PubMed]

20. Haddag, B.; Atlati, S.; Nouari, M.; Moufki, A. Dry machining aeronautical aluminum alloy AA2024-T351: Analysis of cutting forces, chip segmentation and built-up edge formation. Metals 2016, 6, 197. [CrossRef]

21. Rubio, E.M.; Camacho, A.M.; Sánchez-Sola, J.M.; Marcos, M. Chip arrangement in the dry cutting of aluminum alloys. J. Achiev. Mater. Manuf. Eng. 2006, 16, 164-170.

22. López de la Calle, L.N.; Pérez, J.; Llorente, J.J.; Sánchez, J.A. Advanced cutting conditions for the milling of aeronautical alloys. J. Mater. Process. Technol. 2000, 100, 1-11. [CrossRef]

23. Trujillo, F.J. Parametric Analysis in the Dry Machining of UNSA97075 Alloy. Ph.D. Thesis, University of Malaga, Malaga, Spain, 2013.

24. Korkut, I.; Donertas, M.A. The influence of feed rate and cutting speed on the cutting forces, surface roughness and tool chip contact length during face milling. Mater. Des. 2007, 28, 308-312. [CrossRef]

25. Sánchez-Sola, J.M.; Batista, M.; Salguero, J.; Gómez, A.; Marcos, M. Cutting speed-feed based parametric model for macro-geometrical deviations in the dry turning of UNS A92024 al-cu alloys. Key Eng. Mater. 2012, 504-506, 1311-1316. [CrossRef]

26. Otero Huerta, E. Corrosión y Degradación de Materiales, 2nd ed.; Editorial Síntesis, S. A.: Madrid, Spain, 2012; ISBN 978-84-773851-8-9.

27. Huang, I.-W.; Hurley, B.L.; Yang, F.; Buchheit, R.G. Dependence on Temperature, $\mathrm{pH}$, and $\mathrm{Cl}$ in the uniform corrosion of aluminum alloys 2024-T3. 6061-T6, and 7075-T6. Electrochim. Acta 2016, 199, 242-253. [CrossRef]

28. Bienvenido, R.; Díaz Vázquez, J.E.; Botana, J.; Cano, M.J.; Marcos, M.; Díaz-Vázquez, J.E.; Botana, J.; Cano-Iglesias, M.J.; Marcos, M. Preliminary study of the influence of machining conditions in the response to corrosion of UNS-A92024 alloy. Adv. Mater. Res. 2010, 107, 117-121. [CrossRef]

29. Aballe, A.; Bethencourt, M.; Botana, F.J.; Cano, M.J.; Marcos, M. Localized alkaline corrosion of alloy AA5083 in neutral 3.5\% NaCl solution. Corros. Sci. 2001, 43, 1657-1674. [CrossRef]

30. Kamoutsi, H.; Haidemenopoulos, G.N.; Bontozoglou, V.; Pantelakis, S. Corrosion-induced hydrogen embrittlement in aluminum alloy 2024. Corros. Sci. 2006, 48, 1209-1224. [CrossRef]

31. Rout, P.K.; Ghosh, K.S. Effect of microstructural features on stress corrosion cracking behaviour of 7017 and 7150 aluminum alloy. Mater. Today Proc. 2018, 5, 2391-2400. [CrossRef]

32. Song, R.G.; Dietzel, W.; Zhang, B.J.; Liu, W.J.; Tseng, M.K.; Atrens, A. Stress corrosion cracking and hydrogen embrittlement of an Al-Zn-Mg-Cu alloy. Acta Mater. 2004, 52, 4727-4743. [CrossRef]

33. Gómez-Parra, A.; Puerta, F.J.; Rosales, E.I.; González-Madrigal, J.M.; Marcos, M. Study of the influence of cutting parameters on the Ultimate Tensile Strength (UTS) of UNS A92024 alloy dry turned bars. Procedia Eng. 2013, 63, 796-803. [CrossRef]

34. Gómez-Parra, Á.; Puerta, F.J.; Rosales, E.I.; García-Jurado, D.; Mainé, J.M.; Marcos, M. Influence of the dry turning parameters on the Ultimate Tensile Strength (UTS) of UNS A92024 samples. Mater. Sci. Forum 2014, 797, 65-70. [CrossRef]

35. UNE EN ISO 6892-1:2017. Materiales Metálicos. Ensayo de Tracción. Parte 1: Método de Ensayo a Temperatura Ambiente; AENOR: Madrid, Spain, 2017.

36. Servosis SL Serie ME-405. 2012. pp. 1-8. Available online: https://www.servosis.com/fileuploads/ products/sv-sl-me-405.pdf (accessed on 29 June 2018).

(C) 2018 by the authors. Licensee MDPI, Basel, Switzerland. This article is an open access article distributed under the terms and conditions of the Creative Commons Attribution (CC BY) license (http:/ / creativecommons.org/licenses/by/4.0/). 